\title{
The Millennium Challenge Account: Transforming US Foreign Assistance Policy?
}

\section{Steven Radelet}

$\mathrm{I}$ n March, 2002, US President George W. Bush proposed establishing a new 'Millennium Challenge Account' (MCA) that would provide substantial new bilateral US foreign assistance to a select group of low-income countries that are 'ruling justly, investing in their people, and encouraging economic freedom'. In principle, the MCA could bring about the most fundamental changes to US aid policies since the Kennedy administration. The MCA's significance lies partly in its scale, since the $\$ 5$ billion target annual budget proposed by Bush would represent a nearly 50 percent increase over current US aid. Even if the $\$ 5$ billion target is never fully reached - and it seems unlikely that it will, given current US budget realities - the MCA will lead to a significant increase in US aid in the near future. Perhaps even more importantly, however, the new program brings with it the opportunity to improve significantly how the US delivers its foreign aid.

Traditional foreign aid programs around the world have been criticised for a variety of reasons, including the following:

- Aid programs try to achieve conflicting goals, encompassing everything from supporting political allies, encouraging growth, improving health and education, strengthening the environment, responding to humanitarian emergencies, and distributing surplus agricultural production as food aid.

- Too much aid is directed at countries that either are not the poorest countries or that are political allies that do not have policies conducive to using aid effectively or enhancing development more broadly (Collier and Dollar, 2002).

- Donors do not sufficiently involve recipients in program design, and earmark significant funds for their own priorities, leading to a lack of local 'ownership' of, and commitment to, donor-financed programs.

- Aid programs are inefficient, with large bureaucracies imposing high administrative costs on recipients (Easterly, 2002). Donors also tie significant amounts of aid to purchases in their own country, which, by some estimates, reduces its value to recipients by 15-30 percent (Jempa, 1991).

- Donor activities are not well harmonised, with multiple donors financing similar projects with differing design, implementation, monitoring and evaluation systems, which leads to duplication, higher administrative costs for the recipients, and less effective aid flows. For example, in Tanzania in

Steve Radelet is a Senior Fellow at the Center for Global Development in Washington, DC, and was Deputy Assistant Secretary of the US Treasury for Africa, the Middle East, and Asia From January 2000 through June 2002. 
the early 1990s, donors were implementing 15 separate health projects at the same time (Van de Walle, 2001).

- Monitoring and evaluation systems are badly flawed. Donors rarely measure results accurately, so there is little systematic information about what works and what does not.

These criticisms have been levelled at foreign aid programs generally, as well as to specific donors such as the World Bank, the US Agency for International Development (USAID), and the Australian Agency for International Development (AusAID). For example, in a stinging attack Hughes (2003) contends that Australian aid has been highly ineffective in promoting development in the Pacific. She argues not only that aid to the Pacific has failed to spur development, but that it actually has had a negative effect on growth by distorting incentives for the private sector and by creating economic 'rents' that serve to enrich senior officials in the countries that receive aid. Although she does not offer proof of this negative relationship, she concludes that the best solution would be to halt all Australian aid to the Pacific. As a softer alternative, she recommends that AusAID insist on the principle of 'mutual obligation', in which aid funds are separated from recipient country budgets and expended only on evidence of met targets after careful monitoring and auditing of expenditures. Although Hughes' views are in the minority among Australian development specialists and have been hotly contested, they are indicative of some of the criticisms of foreign aid. AusAID's response has been to defend its record and to argue that aid has helped development outcomes in the Pacific to be better than they otherwise would have been (AusAID, 2003).

These debates about the effectiveness of foreign aid were central to the formulation of the MCA. The Bush administration sees the MCA as addressing some (although not all) of the criticisms, because it will differ from current programs in four critical ways. First, it will have narrower and more clearly defined objectives, aimed solely at supporting economic growth and development. Second, it will provide aid to only a select group of low-income countries that are implementing sound development policies. Third, the administration hopes to reduce bureaucratic costs by administering the program through a new, very lean, government corporation called the Millennium Challenge Corporation (MCC). Fourth, the administration plans to give recipient countries a greater say in program design, implementation and evaluation.

In many ways the MCA is a promising new program. However, much work is required before the promise turns into a reality, and it is quite possible that the program will never reach its potential. Many of the details on how the new program will operate remain uncertain. In January, 2004 - 22 months after Bush first proposed the program - Congress finally passed the Fiscal Year 2004 budget that provides the legal authority to initiate the program and $\$ 1$ billion for its first year of operation. The delays were due, in the first instance, to the administration being distracted throughout early 2003 by the invasion of Iraq and its aftermath. In the later congressional process, authorization for the program was combined 
with the overall 2004 spending bill, which was delayed for several months (for reasons having nothing to do with the MCA) until early 2004. In the meantime, as it awaited congressional approval, the administration announced detailed plans only for selecting countries and for creating the new corporation. It has held discussions, but not yet made final decisions about its plans for operations on the ground in recipient countries, program evaluation, or coordination with other existing US aid agencies, particularly USAID. Since the MCA now has received legal authority and funding, many of these details should become clearer during the first half of 2004.

Nevertheless, even if the program is implemented basically as designed, it will not address all criticisms of foreign aid. Most obviously, by introducing a new bilateral program, the MCA does little to improve the harmonization of aid programs. (Note that not all critics see too little harmonization as a problem. In particular, Easterly (2002) calls for more competition between donor agencies, rather than greater collusion. ) Indeed, there is a significant danger that the MCA could exacerbate the lack of coordination, both within the US government and across donor programs, as discussed below. Moreover, with the large amounts of aid involved, the MCA could make macroeconomic management more difficult for recipient countries, and could distort price incentives facing the private sector. Finally, only a small number of countries will qualify for the MCA, and the administration has not developed strategies for countries that do not qualify, or for failed states that might be the breeding grounds for terrorism and international crime.

\section{Narrower Objectives}

US foreign assistance programs, along with those from other governments, suffer from trying to do too many things at once. There are multiple objectives and purposes, often leading to a lack of coherence in everything from broad strategic planning to specific programs on the ground. For example, the US Foreign Assistance Act of 1961, as amended, specifies a remarkable 33 different goals and 75 priority areas for US foreign aid. The most obvious conflict for aid arises between diplomatic and security goals, on the one hand, and long term development goals on the other.

The tension between these goals is a prime reason why aid has had an uneven impact on growth and poverty reduction across countries. When legitimate security goals drive the allocation of resources (such as Cold War politics, or current funding for Pakistan as part of the war on terrorism), much less should be expected in terms of achieving development. It should hardly be surprising that aid delivered during the Cold War or to support Middle East peace has achieved little by way of development results, because that was not its chief goal.

The MCA's sharper focus on economic growth and poverty reduction is meant to reduce these tensions, although they can never be fully eliminated. As a result, the MCA should be able to allocate resources more effectively to meet those goals and allow for clearer evaluation of results, which should help ensure 
that both recipients and the American public get better outcomes from foreign aid. Of course, much depends on the extent to which the program is able to maintain its focus on growth, and is not used simply to support political allies (see Radelet (2003c) for a discussion of how the MCA fits into broader US foreign policy objectives, such as the war on terrorism). This, in turn, will depend on the process used to select countries for the program - the subject to which we now turn.

\section{Selecting for Success?}

A central tenet of the MCA is that aid can be more effective if it is focused on nations with governments that are committed to economic development and poverty reduction. This idea seems to make common sense: foreign assistance should go much further where governments are dedicated to building better schools and clinics, creating good jobs, and rooting out corruption than in countries with dishonest or incompetent governments. In reality, of course, whether or not the idea works in practice will depend on the details of implementation. 'Country selectivity' has gained much currency in recent years, based to a large extent on the research of World Bank economists Craig Burnside, David Dollar, and Paul Collier, which concludes that aid has a positive relationship with growth in countries with good policies and institutions, and little effect in other countries (Burnside and Dollar, 2000; Collier and Dollar, 2002; World Bank, 1998). However, these studies have come under attack from two directions. Several studies challenge the finding that the positive aid/growth relationship depends on good policies, finding instead that aid is positively correlated with growth (with diminishing returns) regardless of the policy environment (for example, Hansen and Tarp, 2000). Other studies have found that the initial results are not robust to new data points and different time frames, and do not find a clear relationship between aid and growth (Easterly, Levine and Roodman, 2003).

While the statistical debate continues, the 'country selectivity' idea seems intuitively correct to development specialists, from a variety of backgrounds, who believe that aid is more likely to work in countries with governments that are committed to development - including some aid critics. For example, few believe that aid did any good in Zaire under the disastrous leadership of Mobuto Sese Seko, while aid played an important supporting role in well-governed Botswana's very rapid development. Hughes (2003) argues that 'AusAID's best projects and programmes have been in countries like Thailand and Indonesia that were sharply focused on growth in the 1970s and 1980s'. Partly because of these beliefs, the Burnside, Dollar and Collier research has heavily influenced several donors, including the World Bank, the Asian Development Bank, and the African Development Bank. All three banks have adopted a Performance-Based Allocation (PBA) system for distributing their concessional loans among eligible borrowers. In the World Bank, a country's allocation depends primarily on its Country Policy and Institutional Assessment (CPIA) score, through which Bank staff rank countries on 20 different policy and institutional criteria. Other factors 
determining allocation are the performance of the country's loan portfolio with the Bank, its average income, and its population (World Bank, 2003a and 2003b). The Asian and African Development Banks use similar, albeit not identical, systems (Asian Development Bank, 2001; African Development Bank, 2001).

There is no question that the idea of 'country selectivity' and the Burnside, Dollar and Collier research is at the core of the MCA country selection process. However, the general idea that good policy matters in making aid more effective only takes us so far. Putting this idea into practice raises an immediate challenge: how should donors determine whether potential recipient countries meet this standard? This question has been the focus of much debate on PBA systems at the multilateral development banks (MDBs), particularly on the choice of indicators, their measurement, weighting, and exceptions to the rules. With respect to the MCA, specifically, are President Bush's criteria of 'ruling justly, investing in their people, and establishing economic freedom' the right ones? And if so, how, precisely, should the US government determine which countries meet these criteria?

At the most general conceptual level, it is hard to argue against Bush's three broad criteria. Surely donors should be inclined to provide more support, all else being equal, to countries with better governance - in the sense of a lower level of corruption, more effective government, and stronger support for democracy. Moreover, recent empirical suggests that countries with better governance have better development outcomes, in the sense of faster economic growth, increased adult literacy, and lower infant mortality (Kaufmann, Kraay and Zoido-Lobatón, 1999). ${ }^{1}$ Similarly, few development experts would argue about the merits of lowincome countries 'investing in their people' to the extent that means investments in basic health and education. 'Investing in economic freedom' is more contentious: although there clearly has been a consensus to move toward more open and flexible markets in low-income countries during the last two decades, debate continues on how far this trend should go and which markets should be liberalised. In all three areas, then, the devil is in the details, as has been discovered in other PBA systems. While most development experts would not argue forcefully against the broad thrust of the three criteria, all would ask: precisely what do they mean, and how should they be measured?

To address this issue, the administration will use 16 specific indicators (see Table 1), grouped into Bush's three broad categories. According to the administration's methodology, countries must score above the median (calculated for all broadly eligible countries) on half or more of the indicators in each of the three groups to qualify for the MCA. That is, countries must surpass the median

1 As with any relationship, there are some exceptions to the rule. Some analysts point to China as a country with poor governance and strong development outcomes. China does score poorly on democracy-related indicators, but on other governance indicators (for example, political stability, government effectiveness, corruption, regulatory quality, and even rule of law), it scores well above the average for countries at similar levels of income (see World Bank Institute governance database at http://www.worldbank.org/wbi/governance/govdata2002/index.html). 
in three of the six 'ruling justly' indicators, two of the four 'investing in people' indicators, and three of the six 'establishing economic freedom' indicators. In addition, a country must score above the median on corruption, regardless of how well it does on all the other indicators.

Table 1: Eligibility Criteria for the MCA

\begin{tabular}{|c|c|}
\hline Indicator & Source \\
\hline \multicolumn{2}{|c|}{ I. Ruling Justly } \\
\hline 1. Control of Corruption & World Bank Institute \\
\hline 2. Rule of Law & World Bank Institute \\
\hline 3. Voice and Accountability & World Bank Institute \\
\hline 4. Government Effectiveness & World Bank Institute \\
\hline 5. Civil Liberties & Freedom House \\
\hline 6. Political Rights & Freedom House \\
\hline \multicolumn{2}{|c|}{ II. Investing in People } \\
\hline 7. Immunization Rate: DPT and Measles & WHO/World Bank \\
\hline 8. Primary Education Completion Rate & World Bank \\
\hline 9. Public Primary Education Spending/GDP & World Bank \\
\hline 10. Public Expenditure on Health/GDP & World Bank \\
\hline \multicolumn{2}{|c|}{ III. Economic Freedom } \\
\hline 11. Country Credit Rating & Institutional Investor \\
\hline 12. Inflation & IMF \\
\hline 13. Regulatory Quality & World Bank Institute \\
\hline 14. Budget Deficit/GDP & IMF/World Bank \\
\hline 15. Trade Policy & Heritage Foundation \\
\hline 16. Days to Start a Business & World Bank \\
\hline
\end{tabular}

Note: To qualify, countries must be above the median on half of the indicators in each of the three sub-groups, and above the median on corruption.

Source: 'Fact Sheet: Millennium Challenge Account', distributed by the administration on 25 November 2002, available at www.cgdev.org.

Using publicly available data and this methodology on the administration's 16 indicators, I have produced an illustrative list of countries that are most likely to qualify for the MCA during its first three years (see Radelet (2003b) for more details on the 16 indicators and the methodology). It is crucial to note that this list is illustrative, rather than official US policy. Although the administration has 
announced that it will follow this procedure in choosing the countries, it has not yet announced its list of qualifying countries, and the list that it ultimately announces (sometime in early 2004) is likely to differ from this illustrative list in some instances.

Moreover, the administration has stressed that the list produced by the 16 indicators is not final - the board of directors of the new Millennium Challenge Corporation (MCC), which will be explained below, can modify the final list under certain circumstances (see the administration's fact sheet at www.cgdev.org/nv/MCA_FactSheetNov.doc). Specifically, in making its final decisions, the board will be 'empowered to take account of data gaps, lags, trends, or other material information, including leadership, related to economic growth and poverty reduction'. This last step introduces some subjectivity into the selection process, which is probably necessary given the weaknesses in the data. However, this discretion opens up the possibility that the ultimate list of qualifying countries will become politicised. There is little question that, to some degree, some pressure to put political allies on the eligibility list is inevitable. But the system has some checks and balances that will modify this impulse in key ways. Most importantly, the administration has announced a very public, transparent system, using public data (not secret US data) to choose the baseline list of countries. To the extent that it deviates form this list, it will have to answer to public scrutiny from Congress and other interested parties. ${ }^{2}$ This public check will not completely stop the administration from making some changes, but it will make it much more difficult, and should modify abuse in the selection process to some extent.

Despite these possible adjustments, the illustrative list determined by the most recent data provides some useful insight as to how the MCA might eventually develop. In the first year, the pool of countries eligible for consideration for the MCA are those with an average annual per capita income below \$1,435 and that are eligible for concessional borrowing from the World Bank. There are 74 countries in this group. Table 2 shows that 11 of these countries might qualify for the MCA during this period, based on data currently available and a strict interpretation of the administration's qualifying procedures. The table also shows that several other countries are very close to qualifying. Three more countries would qualify if the administration slightly altered its criteria to allow scores equal to the median count as passing scores, rather than strictly above the median. Five other countries pass sufficient hurdles, but fail on the corruption indicator - the one indicator that countries must pass in order to qualify. Eight other countries miss qualifying by one hurdle. Thus, the number of qualifying countries easily could expand beyond the 11 that strictly meet the criteria in the first year.

\footnotetext{
${ }^{2}$ This public selection system is one way in which the MCA goes beyond the multilateral development banks' PBA system, since the MDBs' country policy performance scores are not publicly available.
} 
Table 2: Possible Qualifying Countries Using the Administration's Criteria

\begin{tabular}{|c|c|c|c|}
\hline & $\begin{array}{l}\text { Year 1: IDA Eligible } \\
\text { Countries with per } \\
\text { Capita Incomes Less } \\
\text { Than } \$ 1,435\end{array}$ & $\begin{array}{l}\text { Year 2: } \\
\text { Countries with per } \\
\text { Capita Incomes Less } \\
\text { than } \$ 1,435\end{array}$ & 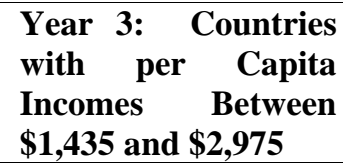 \\
\hline \multicolumn{4}{|c|}{ Qualifying Countries } \\
\hline 1. & Armenia & Armenia & Belize \\
\hline 2. & Bhutan & Bhutan & Bulgaria \\
\hline 3. & Bolivia & Bolivia & Jordan \\
\hline 4. & Ghana & Honduras & Namibia \\
\hline 5. & Honduras & Lesotho & South Africa \\
\hline 6. & Lesotho & Mongolia & St. Vincent \& Grenada. \\
\hline 7. & Mongolia & Nicaragua & \\
\hline 8. & Nicaragua & Philippines & \\
\hline 9. & Senegal & Senegal & \\
\hline 10. & Sri Lanka & Sri Lanka & \\
\hline 11. & Vietnam & Swaziland & \\
\hline 12. & & Vietnam & \\
\hline \multicolumn{4}{|c|}{ Eliminated By Corruption } \\
\hline 1. & Albania & Bangladesh & Romania \\
\hline 2. & Bangladesh & Ecuador & \\
\hline 3. & Malawi & Malawi & \\
\hline 4. & Moldova & Moldova & \\
\hline 5. & Mozambique & Paraguay & \\
\hline 6. & & Ukraine & \\
\hline \multicolumn{4}{|c|}{ Missed by One Indicator } \\
\hline 1. & Benin & Benin & Maldives \\
\hline 2. & Burkina Faso & Burkina Faso & Thailand \\
\hline 3. & Cape Verde & Cape Verde & Tunisia \\
\hline 4. & Georgia & The Gambia & \\
\hline 5. & Guyana & Ghana & \\
\hline 6. & India & Guyana & \\
\hline 7. & Mali & India & \\
\hline 8. & Mauritania & Mali & \\
\hline 9. & Nepal & Mauritania & \\
\hline 10. & Sao Tome and Principe & Morocco & \\
\hline 11. & Togo & Sao Tome and Principe & \\
\hline \multicolumn{4}{|c|}{ Eliminated for Statutory Reasons } \\
\hline 1. & & China & \\
\hline 2. & & Syria & \\
\hline
\end{tabular}

Source: Radelet (2003b). 
The pool of eligible countries will expand slightly in the second year, in line with an increase in program funding to include all countries with average per capita income below $\$ 1,435$, regardless of their borrowing status with the World Bank. This change increases the total number of eligible countries to 87. Of these, 12 qualify in the second year according to a strict interpretation of the process. An additional 17 countries just miss qualifying, either because some of their scores are equal to the median, they fail on corruption, or miss by a single indicator.

The administration proposes sharply expanding the pool of eligible countries in year three (in line with the increase in annual funding to the targeted $\$ 5$ billion) to include the 28 nations with average per capita incomes between \$1,435 and $\$ 2,975$. This group of countries would be judged separately from the 84 countries with average incomes below $\$ 1,435$, with separate median scores to assess country qualification. Adding this last group of nations is controversial, with some analysts (including me) believing that the program should remain focused on the poorest, least developed countries of the world, and should not be expanded to countries that have access to private capital markets. In any case, based on data available today, six of these 28 nations would qualify in year three, as shown in Table 2, and four others would be close to qualifying. Note that these countries are in addition to those that qualify in year two (not instead of), since they compete to qualify as a separate group.

Thus, based on a strict interpretation of the administration's proposal, approximately 18 different countries might qualify for the MCA over the course of the first three years. More than 20 other countries might miss qualifying by just one indicator. Several of these countries could easily qualify within the first few years by improving their scores in one deficient area. Thus 20-25 countries could qualify for the MCA by its fourth or fifth year of operation.

The relatively large MCA budget, combined with the small number of qualifying countries, should provide ample incentive for countries to try to qualify. For the first year, Congress has approved $\$ 1$ billion in funding. If the administration's list of first-year qualifiers ultimately includes, say, 15 countries, the average country could receive $\$ 67$ million. This is equivalent to about onesixth of the average total capital inflows (from aid and other sources) of \$384 per country for IDA-eligible countries (Radelet, 2003b). Ultimately, if the MCA receives a total budget of, say, $\$ 3$ billion (a figure more likely than the $\$ 5$ billion proposed by the president), and 25 countries qualify, the average per country would reach \$120 million per year, equivalent to about one-third of current capital inflows.

This list of countries is not perfect, but it is a reasonable start towards the objective of a selective program. Weaknesses and inconsistencies in the data result in some countries appearing on the list that probably should not qualify, and a few nations do not appear despite having a strong record of using aid effectively. Some changes to the criteria could improve the list. For example, some of the weakest indicators (such as the trade index) could easily be improved over time. The aggregation methodology of counting the number of median scores surpassed 
could be replaced with a simple aggregation method of normalizing scores and then adding them into a composite score, which (while not perfect) would lead to fewer anomalies. In addition, the requirement to exclude all countries with corruption scores below the median should be modified, since the underlying data are not sufficiently robust to make such clear judgments. These and other proposals to improve the selection procedure are discussed in detail elsewhere (Radelet, 2003b). Moreover, using such a highly selective process means that many poor, weakly governed countries are unlikely to qualify for the MCA, making it all the more important for the US to improve its other aid programs, as discussed below. Nevertheless, despite these issues, the proposed system provides a reasonable way to begin distinguishing between nations that show a strong commitment to development and those that do not.

\section{Beyond Selection: Improving the Aid Bureaucracy}

The US foreign aid system is bogged down under a heavy bureaucracy, overly restrictive legislative burdens, and conflicting objectives. As with most donors, the US delivers aid in basically the same way in countries with competent, committed governments as in countries with high levels of corruption and poor development policy. To make the MCA different, the Bush administration has proposed that the program be administered through a new 'government corporation' - the Millennium Challenge Corporation (MCC) — designed to reduce administrative costs and increase effectiveness.

Details on the structure and operations of the MCC are beginning to emerge. The MCC will be governed by a cabinet-level board of directors chaired by the secretary of state and including four non-government appointees, two nominated by each of the majority and minority parties in Congress. The Corporation will be managed by a CEO nominated by the president and approved by the Senate. Staff will be drawn from a variety of government agencies for a limited term. The MCC's biggest advantage is that it would start with a clean slate, and therefore could avoid the bureaucratic procedures and multiple congressional mandates that weaken current aid programs. Its status as separate from any existing department could make it more flexible and responsive, and could help it to attract some topnotch talent.

Establishing a new corporation entails certain risks, however. Dividing the US foreign-assistance program into two major agencies (USAID and the MCC), in addition to several smaller agencies such as the Peace Corps, could impede coordination and increase redundancy. For this reason, many advocates preferred the option of making the MCA a subset of USAID, in order to keep the major aid programs under one leader. Ultimately, however, the administration believed that this structure would undermine the MCA, by subjecting it to the rules and regulations of USAID. Another risk is the size of the MCC staff. The administration hopes to keep MCC small, but its projected staffing level of somewhere between 100 and 200 people seems inordinately so for a program with an annual budget of $\$ 5$ billion. It is also not clear who will represent the MCC on 
the ground in the qualifying countries. Presumably, it will contract out many services, such as monitoring and evaluation, or it might try to work through USAID staff in each country. Nevertheless, there is a risk that the new agency will be understaffed and thus unable to deliver the high-quality operations that will be expected. In addition, having the secretary of state serve as chairman of the board of the MCC could give the department too much control over qualification and allocation decisions, which could compromise the objectivity of the MCC in favour of other foreign policy goals. In short, over time the MCC could be facing all of the same obstacles that are currently facing USAID, especially if the administration does not try to rectify the weaknesses within USAID itself in the meantime.

One of the biggest concerns, therefore, is the impact of the MCC on USAID and the relationship between the two organizations. The MCC is likely to draw staff and resources from USAID, furthering weakening the agency, possibly engendering some resentment, and making cooperation more difficult. Many issues remain uncertain. For example, will USAID continue to operate in the MCA countries, or will it pull out once a country qualifies? On the one hand, having both institutions operating in the same country could be very confusing for recipient countries and unnecessarily duplicate services. On the other, there may be some projects and programs that USAID is better positioned to administer, given its prior experience and established operations in these countries. This issue could prove particularly tricky for borderline countries that qualify for the MCA for several years, then fail to qualify, and then qualify again. Switching back and forth between MCA and USAID programs could be very cumbersome. Similarly, will the MCC operate under new or existing foreign assistance guidelines for procurement of goods and services and other operations? Although more flexible guidelines might seem useful for the MCC, if the two agencies are operating under vastly different rules in the same country, this could lead to serious confusion.

The administration has not yet addressed these questions. If not resolved carefully through strong planning and coordination, the difficulties in operating two foreign assistance programs from two very different parts of the US government are sure to become apparent, and could significantly undermine both MCA and USAID programs.

\section{Designing Better Programs}

Currently, most US foreign assistance is delivered through a countryprogramming approach in which USAID staff members develop a country strategy, design specific interventions, and evaluate the outcomes. This top-down approach has many shortcomings, including the absence of recipient-nation ownership of specific projects, only partial coordination (at best) with the recipient country's overall development strategy, a heavy requirement of USAID staff, and little competition between proposed projects. The administration is planning a different approach with the MCA — building on the basis that MCA-recipient 
nations have an established record of good development policies - that would give recipients much more of the responsibility for program design.

Although details are still under discussion, one possibility is to draw on the 'foundation approach' in which recipients write proposals for various activities and the best ideas receive funding. In this process, the government of an MCA country could write a proposal, for example, to fund a significant portion of its education program. Proposals would spell out the specific actions that the recipient would take and the benchmarks by which success would be measured, pushing recipients to establish concrete goals. In one variation under consideration, government and non-government agencies alike — such as private NGOs, clinics and schools - could write proposals and receive funds, since private agencies implement some of the best development programs.

The foundation approach is already being used by some other new aid organizations, including the Global Alliance for Vaccines and Immunizations (GAVI) and the Global Fund to Fight AIDS, Tuberculosis, and Malaria. This approach would provide a process through which the US government could provide direct budget support (under the right circumstances) and finance development programs (including recurrent costs) in addition to specific projects. It also would be consistent with the recent movement of other donors toward 'pooling' of funds and towards Sector-Wide Approaches (SWAps) to financing health and education programs.

Such an approach would place responsibility for development programs where it belongs - with recipient nations, not with aid agencies. It would ensure that recipient governments set their own priorities and develop their own strategies. If this approach were implemented in a serious, non-superficial way, the MCA would increase recipient-nation ownership of, and commitment to, development programs, which could lead to better results. Some analysts have argued that many MCA countries will initially lack the capacity to develop strong proposals and programs, but the only way they will develop these capacities is if they are given the responsibility to do so and expected to show results. Obviously this approach can only work in those countries that have shown, and continue to show, a real commitment to development, and it will only work if recipients are truly held accountable for results.

Thus the final, and perhaps most crucial, element for the MCA to succeed is a serious monitoring and evaluation (M\&E) process. Most aid agencies have weak and superficial M\&E processes, and if the MCA follows this pattern it is doomed to fail. Effective M\&E is critical for keeping funded programs on track to meet their goals, guiding the allocation of resources towards successful activities and away from failures, and ensuring that the lessons learned from ongoing activities - both successes and failures - inform the design of new projects and programs.

Two distinct kinds of M\&E are required: tracking finances and monitoring substantive targets. Financial accountability should ensure that funds are spent where they are supposed to be spent, projects remain within budgets, regulations on procurement and payment are followed, and funds are not stolen. Substantive accountability focuses on attaining specified benchmarks, such as training so 
many teachers, building a designated number of schools, or increasing test scores by a certain amount. M\&E must be incorporated into projects and programs from the outset, not added on as an afterthought halfway through the process. Both internal audits (carried out by the grantees) and external audits (carried out directly by the MCC or a contractor to the MCC) will be needed to ensure compliance and high standards. A small number of programs should be evaluated through randomised trials, as suggested by Kremer (2003) and others.

Of course, providing recipients with a greater say in program design, implementation, and evaluation entails some risks. Giving recipients greater flexibility can only work in countries that demonstrate the strongest commitment to development - exactly the MCA's target countries. With greater flexibility, however, should come greater responsibility. The US should expect strong results from the MCA, and hold grantees accountable for achieving the goals specified in their programs. It should generously fund programs that achieve results, and reduce or eliminate funding for programs that do not. Whether or not the MCA can ultimately move in this direction remains to be seen. If it can, it could lead to positive changes in US and other aid programs; if it cannot, it could quickly begin to resemble most other aid programs.

These issues and concerns go well beyond the MCA, since introducing a new MCA (even if it runs well) will not constitute a complete foreign assistance strategy for the US. Since only a small number of countries will receive MCA funding, the new program is at best only a partial strategy for US foreign assistance. Indeed, because the MCA focuses on those countries with governments that have shown the strongest commitment to development, it essentially deals with the easiest cases among poor countries.

To really make US foreign aid work effectively, the Bush administration must develop comparable strategies for different groups of nations that fail to qualify for MCA funding, whether they just miss qualifying or are failed states mired in perpetual conflict. Different approaches are required for different circumstances, with varying design procedures, delivery mechanisms, objectives and $M \& E$ processes. For example, in countries that just miss qualifying for the MCA, allowing recipients to write limited proposals focused on the specific areas where they fall short of qualification could strengthen traditional aid programs. In countries with weaker governments, donor funding should continue to concentrate on specific projects, but with streamlined contracting and procurement procedures to make projects more cost-effective. Where governments are weak (or part of the problem), aid should be channelled through NGOs and other service providers on the ground. In some circumstances, no aid should be provided at all. In effect, the MCA should be seen as just one of several tools available to address US goals in low-income countries.

\section{A Unilateral Approach}

There are in fact two major Bush administration foreign aid initiatives: the MCA and the 'Emergency Plan for AIDS Relief', which will provide $\$ 10$ billion over 
the next five years (in addition to $\$ 5$ billion already in the pipeline) to fight HIV/AIDS around the world, with a special focus on Africa and the Caribbean. All of the MCA money and over 90 per cent of the HIV/AIDS funds will go through US bilateral programs. The unilateral nature of these initiatives reveals the administration's distrust of both its own institutions and multilateral aid agencies.

With the MCA the administration could have spearheaded a multilateral initiative with the same basic design: choosing countries selectively, delivering aid more efficiently with more recipient-country input, a smaller bureaucracy, and results-based management. There are three likely reasons that it chose the unilateral route:

- Political. In the face of mounting criticism that the US does too little to fight global poverty, the administration wanted to announce a significant, clearly American initiative at the International Conference on Financing for Development in Monterrey in March 2001. A multilateral effort, even if spearheaded by the US, quickly would have lost much of its brand identification as a US initiative.

- Substance. In two key areas of the MCA - country selection and the expectation of results - the administration does not trust the multilateral institutions to maintain high standards. It is not convinced by the World Bank's claims that it has become more selective in its allocation decisions. Many in the administration believe that to turn the MCA over to a multilateral organization would doom it to large bureaucratic costs and weak results. In the administration's view, the US would be expected to be the largest donor but would cede much of its control to the other donors. In a unilateral approach, the US can maintain complete control over all aspects of the program. Hughes (2003) makes a similar argument about Australian aid, concluding that the bulk of it should be provided unilaterally, as she believes the multilateral institutions have failed to maintain high standards.

- Ideological. The unilateral approach to foreign aid is part of a much larger pattern of the administration's scepticism of multilateral approaches to foreign policy. There are many other examples, including terminating negotiations on the Kyoto Protocol on Climate Change, rejection of the Rome Statute of the International Criminal Court, and withdrawal from the antiballistic missile (ABM) treaty.

The main arguments in favour of a multilateral approach for the MCA are laid out by van de Walle (2003) and Sperling and Hart (2003). First, a multilateral approach would be less cumbersome and confusing to recipient countries that are overwhelmed by the myriad proposal processes, financial mechanisms and reporting systems used by different donors. Second, it would create more leverage for US funds, since other donors would contribute something for each dollar the US spends. Third, a multilateral approach would reduce the pressure to allocate funds on a political basis (although the MCA's public selection process goes some 
distance toward easing this concern; moreover, multilateral organizations are far from immune to political pressures). Fourth, a multilateral approach would be less immune to earmarking, tied aid, and other burdens imposed by Congress, although it would be subject to its own bureaucracy.

Despite these concerns, under a best-case scenario it is possible that a unilateral MCA could have a positive impact on other donors and on donor harmonization. By itself, the MCA, at \$5 billion, will account for the equivalent of 9 percent of current worldwide ODA flows of $\$ 58$ billion - not an overwhelming share, but far from insignificant. Its proposed recipient-driven, program-based approach could influence other donors to try similar strategies. Moreover, recipient proposals used for the MCA could be the basis for other donors to co-finance the same activities. For example, consider the Education for All (EFA) initiative, in which donors agreed in 2000 to provide funding for countries that produced strong education strategies. The EFA strategies could be the basis for MCA funding in qualifying countries, with the US and other donors cooperatively financing parts of the same basic education plan.

Much will depend on the extent to which the new corporation is willing to work cooperatively with recipient governments and other donors to reduce the administrative burden on aid recipients. If the US stridently insists on using its own unique proposal format and reporting systems the MCA will set back recent efforts to improve coordination, and could become a stumbling block for greater harmonization. If, however, there is a serious effort to establish rigorous procedural norms that a majority of donors can accept, including expecting high performance standards, the MCA could be a small step in the right direction of improving donor harmonization and the performance of foreign aid .

The MCA is only in its very initial stages, having finally received approval and budgetary authority for its first year of operation. Many aspects of the program are promising: its de-politicised country selection process (which should moderate, albeit not fully eliminate, political pressures in the selection process); its relatively large funding ( $\$ 1$ billion in the first year); its country-owned proposal process; and its emphasis on achieving results. Of course, there is a very real possibility that the program will not live up to its promise, and will ultimately operate like many other aid programs, so some scepticism is warranted. But the MCA clearly signals a fundamental shift in the thinking behind US foreign aid programs, holding out the possibility of larger and more effective foreign aid in the years to come. Working to achieve that goal is surely in America's best interests, as well as in the interests of low-income countries around the world.

\section{References}

African Development Bank (2001), 'Performance-Based Allocation of ADF Resources', www.adb.org/Documents/Policies/ADF/Performance_Based_Allocation/.

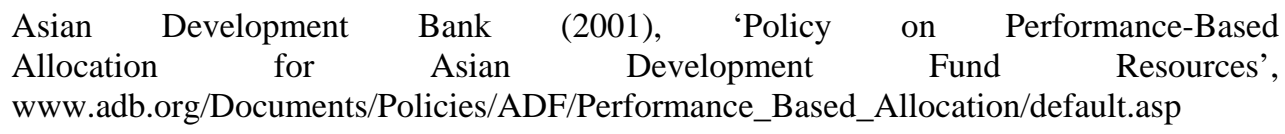


AusAID (2003), 'Why our AID to the Pacific is so Important', www.ausaid.gov.au/hottopics/topic.cfm?Id=2157_7967_5228_415_6958.

Burnside, C. and D. Dollar (2000), ‘Aid, Policies, and Growth', American Economic Review 90(4)(September):847-68.

Collier, P. and D. Dollar (2002), 'Aid Allocation and Poverty Reduction', European Economic Review 45(1):1-26.

Easterly, W. (2002), 'The Cartel of Good Intentions: Bureaucracy versus Markets in Foreign Aid', Working Paper No. 4 (March), Center for Global Development, Washington DC.

Easterly, W., R. Levine and D. Roodman (2003), 'New Data, New Doubts: Revisiting 'Aid, Policies and Growth”, Working Paper No. 26 (February), Center for Global Development, Washington DC.

Hansen, H. and F. Tarp (2000), 'Aid Effectiveness Disputed', Journal of International Development 12(3):375-98.

Hughes, H. (2003), 'Aid has failed the Pacific', Issue Analysis No. 33, The Centre for Independent Studies, www.cis.org.au/IssueAnalysis/ia33/ia33.htm.

Jempa, C. (1991), The Tying of Aid, OECD Development Center, Paris

Kaufmann, D., A. Kraay, and P. Zoido-Lobatón (1999), 'Governance Matters’, Working Paper 2196 (October), Policy Research, World Bank, Washington DC.

Kremer, M. (2003), 'Randomized Evaluations of Educational Programs in Developing Countries: Some Lessons’, American Economic Review 93(2)(May):102-106.

Radelet, S. (2003a), 'Will the Millennium Challenge Account be Different?', The Washington Quarterly (Spring):171-188.

Radelet, S. (2003b), Challenging Foreign Aid: A Policymakers Guide the to Millennium Challenge Account, Center for Global Development, Washington DC.

Radelet, S. (2003c), 'Bush and Foreign Aid', Foreign Affairs 82(5) (September/October):104-117.

Sperling, G. and T. Hart (2003), 'A Better Way to Fight Global Poverty: Broadening the Millennium Challenge Account, Foreign Affairs 82(2) (March/April): 9-14

Van de Walle, N. (2001), African Economies and the Politics of Permanent Crisis, 19791999, Cambridge University Press, Cambridge.

Van de Walle, N. (2003), 'A Comment on the MCA Proposals', Center for Global Development, Washington DC, www.cgdev.org/briefs/vandewalle_20030109.pdf.

World Bank (1998), Assessing Aid: What Works, What Doesn't, and Why, World Bank, Washington DC. 
World Bank (2002), A Case for Aid: Building a Consensus for Development Assistance. World Bank, Washington DC.

World Bank (2003a), 'IDA's Performance-Based Allocation System: Current and Emerging Issues', Report No. 27082 (October), World Bank, Washington DC, wwwwds.worldbank.org/servlet/WDS_IBank_Servlet?pcont=details\&eid=000160016_2003102 7122520 .

World Bank (2003b), 'Allocating IDA Funds Based on Performance: Fourth Annual Report on IDA's Country Assessment and Allocation Process', World Bank, Washington DC, (April), siteresources.worldbank.org/IDA/Resources/PBAAR4.pdf

Some parts of this paper are drawn from an earlier paper 'Will the Millennium Challenge Account be Different?' The Washington Quarterly, Spring 2003:171188, and from 'Challenging Foreign Aid: A Policymakers Guide the to Millennium Challenge Account' published by the Center for Global Development (Washington, DC). My thanks to Ross McLeod for suggesting I write this article, and to two anonymous referees whose generous comments improved the quality of the final product. 